\title{
Evaluation of Working Memory in Children with Attention Deficit/Hyperactivity Disorder
}

\author{
Tais de Lima Ferreira1, Clay Brites', Cíntia Alves Salgado Azoni², Sylvia Maria Ciasca1 \\ ${ }^{1}$ Department of Neurology, Research Laboratory of Learning and Attention Disorders (DISAPRE), School of \\ Medical Sciences, State University of Campinas (UNICAMP), Campinas, Brazil \\ ${ }^{2}$ Department of the Speech and Language Pathology, Federal University of Rio Grande do Norte (UFRN), Natal, \\ Brazil \\ Email: ferr.tais@gmail.com
}

Received 15 August 2015; accepted 5 October 2015; published 8 October 2015

Copyright (C) 2015 by authors and Scientific Research Publishing Inc.

This work is licensed under the Creative Commons Attribution International License (CC BY).

http://creativecommons.org/licenses/by/4.0/

(c) (i) Open Access

\begin{abstract}
Purpose: Evaluate the auditory and visual components of working memory in 60 students of both genders. The students were divided into two groups: an experimental group (EG) comprising 30 children with Attention Deficit Hyperactivity Disorder (ADHD) and a control group (CG) consisting of 30 children with neither attention deficits nor learning disabilities. The study found that EG exhibited lower performance than CG. A comparison of two types of working memory: auditory and visual indicated that subjects with ADHD performed best in auditory working memory, while CG subjects performed best in visual working memory. It was also noted that the performance of both groups suffered phonologically and semantically analogous interference effects and temporal effects with greater prejudice to the experimental group.
\end{abstract}

\section{Keywords}

Working Memory, Evaluation, ADHD, Language

\section{Introduction}

Attention Deficit Hyperactivity Disorder (ADHD) is one of the most common neurodevelopmental disorders in children and the most frequent diagnosis in clinical neuropsychiatry (Barkley, 2008; Walshaw, Alloy, \& Sabb, 2010). Constituting a multifactorial heterogeneous disorder, ADHD presents significant challenges involving attention deficits, excessive motor activity and impulsiveness. Anatomical, biochemical, neurophysiological and functional studies highlight the involvement of specific brain circuits in ADHD, demonstrating its neurobiolog-

How to cite this paper: de Lima Ferreira, T., Brites, C., Azoni, C. A. S., \& Ciasca, S. M. (2015). Evaluation of Working Memory in Children with Attention Deficit/Hyperactivity Disorder. Psychology, 6, 1581-1588.

http://dx.doi.org/10.4236/psych.2015.613155 
ical basis (APA, 1994; Sánchez-Mora, Ribasés, Mulas et al., 2012; Mulas, Gandía, Roca et al., 2012).

The current prevalence rates of children and adolescents with ADHD in school range from $4.2 \%$ to $6.3 \%$ (Rohde, 2008; Polanczyk, Laranjeira, Zaleski et al., 2010). More prevalent among boys than girls, the discrepancy can vary from 2 to 1 in epidemiological studies to 9 to 1 in clinical ones (Golfeto \& Barbosa, 2004).

ADHD gives rise to impairments in academic, behavioral and social aspects of daily life, significantly interfering in family and school ambiences to the child's detriment. Most of these effects result from defective processing of higher frontal and prefrontal cortical functions fundamental to attention from its primary inception to more specialized functions, e.g., executive, including working memory (WM) (Abad-Mas, Ruiz-Andres, Moreno-Madrid et al., 2011).

Working memory consists in the rapid manipulation of data required to perform such complex cognitive tasks as language comprehension, learning and reasoning. It contributes to long-term memory (LTM) and its relationship with intelligence, reasoning and problem solving. WM is involved in temporarily storing and processing information, characterized by a system of limited capacity, responsible for briefly storing data. It is monitored by the central executive system, which controls the flow of information to its phonological (articulatory) loop, visuospatial sketchpad and episodic buffer subsystems (Baddeley, 2000).

The phonological loop stores verbal data and comprises two components: phonological storage and articulatory rehearsal (subvocal feedback). Phonological storage is integral to short-term retention of auditory data subject to rapid deterioration. Articulatory rehearsal feeds back information, storing it in memory until it can be consolidated in other mnemonic levels, thus avoiding deterioration. It plays a critical role in language development, vocabulary acquisition and the phonological process, particularly in early childhood (Baddeley, 2000).

The nature of the effects of similarity in working and long-term memory has been the focus of research seeking to determine similarities and differences between them. Hasselhorn and Grube found that phonological similarity is much greater than semantic similarity in terms of WM, whereas semantic similarity is more significant in LTM (Hasselhorn \& Grube, 2003). These findings are used to buttress the premise that the nature of WM is phonological, while that of LTM is semantic. According to Lovatt, Avons, \& Masterson (2000), recall of phonologically similar words (such as lata, pata, and mata) is hindered by acoustic confusion, occasioning difficulty in rapid repetition of words and impairing articulatory rehearsal. Articulatory suppression is another significant influence on phonological memory. For Uehara \& Landeira-Fernandez (2010), the effect of articulatory suppression relates to incapacity to activate articulatory rehearsal as the result of distraction, e.g., the emission of a meaningless sound during evocation, causing a significant decline in the child's ability to perform the task. Word length is another factor affecting WM as long words evoke shorter memory spans than short ones (Hasselhorn \& Grube, 2000).

The visuospatial sketchpad processes and stores visual and spatial data and verbal information encoded in images. It is instrumental in recalling shapes, colors, location and velocity of objects and motion tasks involving spatial planning. Some researchers regard it as a link between visual and spatial data. The interface between the visuospatial sketchpad and the phonological loop renders the processing of these stimuli dependent on verbal encoding rather than physical properties (Lopes, Lopes, \& Galera, 2005).

Andrade (2002) tested children with ADHD in the repetition of bi- and tri-syllabic invented words before and after the use of methylphenidate (MPH). The study found that repetition was impaired in the pre-medication stage and that the use of MPH did not significantly alter performance. The findings suggest consideration of changes in cortical regions beyond the prefrontal and frontal in children with ADHD, as well as in the relationship between ADHD and learning disorders.

Children with behaviors characteristic of impulsivity and inattention present alterations in perceptual-motor tests and consequent impairment in visuospatial memory. In children with attention deficits, impaired phonological and visuospatial storage in WM are associated with inattention and inability to filter out irrelevant stimuli (Kofler, Rapport, Bolden et al., 2010; Vancer, Ferrin, Winther et al., 2013).

Given the preceding circumstances, the study's objective was to evaluate whether there are performance differences between auditory and visual working memory in children with ADHD.

\section{Methodology}

\subsection{Participants}

Study subjects were 60 students, ages 7 years, 1 month to 10 years, 11 months, with a mean age of 8.6 years, 
enrolled between the 1st and 5th year of public elementary school. The subjects were divided into two groups matched for age: an experimental group (EG), comprising children diagnosed with ADHD, and a control group (CG), consisting of children with neither attention nor learning deficits.

Twenty-five male (83.33\%) and five female (16.67\%) students constituted the experimental group. Potential participants were referred for interdisciplinary (neuropsychological, speech therapy, psycho-educational, psychiatric and neurological) diagnosis at UNICAMP's Research Laboratory, and only those with ADHD (combined subtype) confirmed by rigorous diagnostic evidence based on DSM-IV were included in the study. Other criteria required for inclusion were an intelligence quotient (IQ) within the normal range (>80), no complaint of sensory or motor deficits, nonuse of psychotropic medication during the evaluation process, absence of any associated neurological symptoms and parental authorization in the form of a signed informed consent form.

The control group comprises 12 male (40\%) and 18 female (60\%) students, who were evaluated in their public school in Campinas, SP and selected on their teachers' confirmation of satisfactory performance with no evidence of attention deficits or learning disabilities. The participants were referred for interdisciplinary (neurological, neuropsychological and speech language therapy) diagnosis at UNICAMP's Research Laboratory. CG was matched with EG for age, and subjects underwent neuropsychological evaluation by a psychologist. Other criteria required for CG inclusion were IQ within the normal range (>80), no complaint of sensory or motor deficits), nonuse of psychotropic medications, absence of any associated neurological symptoms and a signed parental informed consent form.

\subsection{Instruments}

Subjects undertook Ferreira's proposed adaptation of the Working Memory Assessment Protocol, consisting of visual and auditory tests with tasks of free serial recall in direct and reverse order, repetition of words and nonwords and task spans in forward and reverse order for auditory and visual data (Ferreira, 2011). The protocol is linguistically balanced according to the articulatory complexity of speech to Portuguese, word length (bi-, tri-, and polysyllabic) and degree of familiarity. The words, which are common in children's vocabulary, conform to constant/vowel rules and have short, medium and long lengths (Andrade, 2003; Ferreira, 2011).

The protocol comprises six steps: repetition in direct order, free recall, verbal span, visual span, repetition of nonwords and recall in reverse order. The initial two steps present lists of words that are phonologically or semantically similar or dissimilar.

In step 1, the serial repetition lists comprise bi- and tri-syllabic words with like phonology and dissimilar semantics (bola/cola/rola) (malote/pacote/calote); words with dissimilar phonology and like semantics (maçã/ pera/mamão); and words with dissimilar phonology and semantics (velha/fome/bicho). In step 2, the free repetition lists involve polysyllabic words with complex phonology and dissimilar semantics (computador/mecânico/ macacada/livramento); words with dissimilar phonology and like semantics (color) (anel/jarra/ombro/amarelo/ verde/vermelho/azul/disco/cachorro); bi-syllabic words with like phonology and dissimilar semantics (mata/ bata/pata/cata/chata/lata); and polysyllabic words with dissimilar phonology and semantics (secretaria/escorregador/computador/framboesa). The lists in Step 3 (verbal span) consist of bi-syllabic words with like phonology (vela/mela/tela) and with dissimilar phonology and semantics (saco/neto/ovo). Step 4 (visual span) uses cards of diverse colors (white/black/blue/red/green/pink/yellow), which must be remembered in forward and reverse order, according to their presentation by the test administrator. Step 5 involves repetition of bi- and tri-syllabic nonwords. Finally, step 6 involves the recording of bi-syllabic words in reverse order.

The protocol's implementation requires 20 to 30 minutes, depending on the subject's necessities.

\subsection{Procedures}

This study was approved by the Faculty of Medical Sciences, UNICAMP Research Ethics Committee (Opinion No. 1064/2008). EG subjects were individually assessed in treatment rooms at the Research Laboratory in the Clinical Hospital of UNICAMP. CG subjects were evaluated in their school. Implementation of the Working Memory Assessment Protocol test took an average of 25 minutes per child (Ferreira, 2011).

The following tests were used for statistical analysis: a) Mann-Whitney to determine differences between the groups; b) the Friedman test to ascertain differences among studied conditions, compared concurrently; c) the Wilcoxon signed-rank test, adjusted by Bonferroni correction (Statistical Package for Social Sciences, version 17.0), to identify pair-differences when statistically significant differences were found; and d) a likelihood ratio 
test, with a significance level of $5 \%(p<0.5)$ to determine differences between genders in various age categories.

\section{Results}

The ages of the subjects in the studied groups (EG and CG) varied from 7 years, 1 month, to 10 years, 11 months. Characterization of the sample with respect to age indicated no significant difference between the groups, thus confirming homogeneity compared to age variable $(p=0.884)$. The Mann-Whitney test indicated an overall mean age of 8.82 years (Table 1 ).

The subjects' age distribution was analyzed, using the Mann-Whitney test. According to its statistical analysis, there was homogeneity between the study groups $(p=0.084)$. To ascertain possible group differences for age variable, the likelihood ratio test, where $p=0.851$, was used (Table 2).

Gender differences in terms of age were assessed, using the Mann-Whitney test, which indicated no significant differences ( $p=0.572)$ (Table 3$)$.

The two groups differ significantly in all scores of the Working Memory Assessment Protocol, according to the statistical analysis of the Mann-Whitney test (Table 4).

Due to the occurrence of statistically significant differences between subtests, the Wilcoxon signed-rank test, adjusted by Bonferroni correction, was used to identify the conditions under which they differ. Table 4 shows statistically significant differences between subtests $1 \mathrm{~A} / 1 \mathrm{~B}, 1 \mathrm{~A} / 1 \mathrm{C}$, and $1 \mathrm{~B} / 1 \mathrm{C}$. In regard to free repetition, there were no statistically significant differences between the analyzed pairs in EG. In GC, only the pairs 2B/2A, 2C/2B, 2D/2B, and 2E/2B showed statistically significant differences (Table 5).

\section{Discussion}

The study's findings enable the creation of a likely profile of functioning auditory and visual WM in children

\begin{tabular}{cccccccc}
\multicolumn{6}{l}{ Table 1. Group age difference. } \\
\hline Group & N & Mean Age & SD & Minimum Age & Maximum Age & 50 Percentile & $\boldsymbol{p}^{\text {a }}$ value \\
\hline EG & 30 & 8.80 & 1.03 & 7.00 & 10.00 & 9.00 & \\
CG & 30 & 8.83 & 1.05 & 7.00 & 10.00 & 9.00 & 0.884 \\
Total & 60 & 8.82 & 1.03 & 7.00 & 10.00 & 9.00 & \\
\hline
\end{tabular}

Legend: SD: standard deviation; N: number of subjects; ${ }^{\mathrm{a}}$ Mann-Whitney test.

Table 2. Group age distribution.

\begin{tabular}{cccc}
\hline Years Old & EG & CG & $\boldsymbol{p}^{\text {a value }}$ \\
\hline 7 & 4 & 4 & \\
8 & 7 & 7 & 0.851 \\
9 & 10 & 9 & \\
10 & 9 & 10 & \\
\hline
\end{tabular}

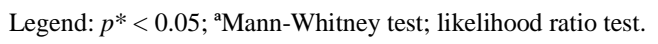

Table 3. Gender distribuition.

\begin{tabular}{ccccc}
\hline Gender & $\mathbf{n}$ & Mean & SD & $\boldsymbol{p}^{\mathbf{a}}$ value \\
Male & 37 & 8.77 & 1.01 & 0.572 \\
Female & 23 & 8.90 & 1.09 & \\
Total & 60 & 8.82 & 1.03 & \\
\hline
\end{tabular}

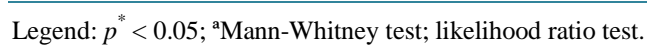


Table 4. Group performance in Working Memory Assessment Protocol (WMAP).

\begin{tabular}{|c|c|c|c|c|c|c|}
\hline \multicolumn{4}{|c|}{ EG } & \multicolumn{3}{|c|}{ CG } \\
\hline & Subtest & Mean & SD & Mean & SD & $p^{\text {a }}$ value \\
\hline \multirow{3}{*}{ Serial Repetition } & $1 \mathrm{~A}$ & 6.77 & 1.37 & 7.75 & 0.88 & $0.005^{*}$ \\
\hline & $1 \mathrm{~B}$ & 8.18 & 0.80 & 8.75 & 0.50 & $0.002^{*}$ \\
\hline & $1 \mathrm{C}$ & 4.35 & 1.31 & 5.87 & 1.07 & $<0.001^{*}$ \\
\hline \multirow{5}{*}{ Free Repetition } & $2 \mathrm{~A}$ & 2.83 & 1.09 & 4.17 & 1.23 & $<0.001^{*}$ \\
\hline & $2 B$ & 4.03 & 1.56 & 5.70 & 1.49 & $<0.001^{*}$ \\
\hline & $2 \mathrm{C}$ & 3.23 & 1.25 & 3.97 & 1.19 & $0.028^{*}$ \\
\hline & $2 \mathrm{D}$ & 3.17 & 1.02 & 4.03 & 0.96 & $<0.001^{*}$ \\
\hline & $2 \mathrm{E}$ & 2.80 & 1.22 & 4.10 & 1.06 & $<0.001^{*}$ \\
\hline \multirow{2}{*}{ Verbal Span } & $3 \mathrm{~A}$ & 3.63 & 0.72 & 4.17 & 0.46 & $0.002^{*}$ \\
\hline & 3B & 3.00 & 0.64 & 3.53 & 0.68 & $0.006^{*}$ \\
\hline \multirow{2}{*}{ Visual Span } & $4 \mathrm{~A}$ & 3.10 & 1.35 & 5.67 & 1.27 & $<0.001^{*}$ \\
\hline & $4 \mathrm{~B}$ & 2.63 & 1.33 & 4.90 & 1.35 & $<0.001^{*}$ \\
\hline \multirow{2}{*}{ Word Repetition } & $5 \mathrm{~A}$ & 14.50 & 0.97 & 15.00 & 0.00 & $0.003^{*}$ \\
\hline & $5 B$ & 14.43 & 0.77 & 15.00 & 0.00 & $<0.001^{*}$ \\
\hline Repetition, Reverse Order & 6 & 1.57 & 1.31 & 3.03 & 1.00 & $<0.001^{*}$ \\
\hline WMAP Total & & 75.50 & 8.26 & 92.72 & 5.66 & $<0.001^{*}$ \\
\hline
\end{tabular}

Legend: (SD) Standard Deviation; ${ }^{*} p<0.05$; ${ }^{a}$ Mann-Whitney test; 1A: 2- and 3-syllable words with like phonology and dissimilar semantics; $1 \mathrm{~B}$ : 2-syllable words with dissimilar phonology and like semantics; equal; 1C: 2-syllable words with dissimilar phonology and semantics; 2A: polysyllabic words with complex phonology and dissimilar semantics; 2B: words with dissimilar phonology and like semantics; 2C: 2-syllable words with like phonology and dissimilar semantics; 2D: words with dissimilar phonology and semantics; 2E: polysyllabic words with dissimilar phonology and semantics; 3A: span of words with dissimilar phonology and semantics; 3B: span of words with like phonology and dissimilar semantics; 4A: visual span, direct order; 4B: visual span, reverse order; 5A: no 2-syllable words; 5B: no 3-syllable words.

Table 5. Comparison between subtest pairs in serial and free recall.

\begin{tabular}{ccc}
\hline & EG & CG \\
\hline Pairs & $p^{\text {a }}$ value & $p^{\text {a }}$ value \\
\hline 1A/1B & $<0.001^{*}$ & $<0.001^{*}$ \\
1A/1C & $<0.001^{*}$ & $<0.001^{*}$ \\
1B/1C & $<0.001^{*}$ & $<0.001^{*}$ \\
Alfa de Bonferroni & $=0.016952^{* *}$ & $=0.016952^{* *}$ \\
2B/2A & 0.001 & $<0.001^{* *}$ \\
2C/2A & 0.131 & 0.429 \\
2D/2A & 0.188 & 0.774 \\
2E/2A & 0.719 \\
2C/2B & 0.629 & $<0.001^{* *}$ \\
2D/2B & 0.023 & $<0.001^{* *}$ \\
2E/2B & 0.007 & $<0.001^{* *}$ \\
2D/2C & 0.001 & 0.850 \\
2E/2C & 0.804 & 0.483 \\
2E/2D & 0.093 & 0.731 \\
Alfa de Bonferroni & 0.187 & $<0.001488$ \\
3A/3B & $<0.001488$ & $0.001^{* *}$ \\
4A/4B & $0.002^{* *}$ & $0.005^{* *}$
\end{tabular}

Legend: ${ }^{*} p<0.05$; ${ }^{a}$ Friedmann test; ${ }^{* *}$ Wilcoxon test; $1 \mathrm{~A}$ : 2- and 3-syllable words with like phonology and dissimilar semantics; 1B: 2-syllable words with dissimilar phonology and like semantics; 1C: 2-syllable words with dissimilar phonology and semantics; 2A: polysyllabic words with complex phonology and dissimilar semantics; 2B: words with dissimilar phonology and like semantics; 2C: 2-syllable words with like phonology and dissimilar semantics; 2D: words with dissimilar phonology and semantic; 2E: polysyllabic words with dissimilar phonology and semantics. Bonferroni alpha $<0.001488<0.001488 ; 3 \mathrm{~A}=$ auditory span with bi-syllabic word with like phonology and dissimilar semantics; 3B: auditory span with dissimilar phonology and semantics; 4A: visual span, direct order; 4B: visual span, reverse order. 
with ADHD. In general, EG subjects evidenced significantly lower performance in all tests than their CG counterparts did. This result relates to changes in attention and executive functions in children with ADHD, as noted in the literature (Walshaw, Alloy, \& Sabb, 2010; Abad-Mas, Ruiz-Andres, \& Moreno-Madri, 2011; Schoemaker, Bunte, Wiebe et al., 2012). In comparing performance in auditory and visual tests, EG subjects performed better in the former. These findings conform to data obtained by Andrade, whose study objectives did not include comparing auditory and visual test performance (Andrade, 2002).

In considering the effect of phonological similarity, both groups experienced the greatest difficulty in effectively recalling lists of words, but EG underperformed when compared to CG. It should be noted that when EG test data in repetition of tri- and five-syllabic words with like phonology and dissimilar semantics, dissimilar phonology and like semantics, and dissimilar phonology and semantics were analyzed, average performance was lowest in the absence of semantic effect, followed by phonologically similar and semantically different words and finally words with dissimilar phonology and like semantics. The difficulty presented by EG subjects is explained in the literature by the fact that, in individuals with ADHD, the effect of phonological similarity increases the likelihood of errors resulting from acoustical confusion and is exacerbated by the problems arising from greater mental exertion and lower attentional performance (Li, Schweickert, \& Gandour, 2000; Schweitzer, Faber, Grafton et al., 2000; Andrade, 2002; Tiffin-Richards, Hasselhorn et al., 2008; Kofler, Rapport, Bolden et al., 2010; Ferreira, 2011). Another point raised in the literature is that children with ADHD use neuronal pathways that are less efficient in solving tasks involving working memory, as well as those related to executive functioning and data manipulation (Farrel, 2006).

The positive effect of words with dissimilar phonology and like semantics on serial recall in direct order and on free recall is evident for both groups. Repetition is facilitated since the meaning of the words to be recalled is accessible and associations among them can be made. Semantic similarity also facilitates free recall, aiding memory by enabling word associations. The improvement in EG subjects, however, was significantly less than that observed in CG subjects since children with ADHD make less efficient or even no use of semantic association strategies (Andrade, 2002; Kofler, Rapport, Bolden et al., 2010).

Concerning recall of polysyllabic words with complex phonology or dissimilar phonology and semantics, little difference was observed. Recall was adversely affected by word length with greatest impact on EG. According to Andrade, this occurs because children with ADHD do not sustain attention for sufficient time to hear a long word to its end (Andrade, 2002). Furthermore, the longer the word's length, the longer is its articulation and the greater is the effect of time on the degradation of auditory data, negatively affecting the span. In relation to word length, Rodrigues \& Befi-Lopes (2009) note that research indicates that the best repetition of word sequences occurs when the time of articulation required to pronounce phonemes, syllables, words or pseudowords is less.

Overall, no significant difference was observed between EG and CG in the repetition of lists of bi- and trisyllabic nonwords, but individuals in the latter group showed superior performance. In this type of test, children do not use semantic or lexical props to facilitate recall. It is possible that the subjects relied solely on phonological aspects to remember, suggesting that working memory depends not only on attention but on phonological processing as well.

In regard to the auditory span, EG subjects were able to recall 3.63 and 3.00 words, respectively, for bi-syllabic words with dissimilar phonology and semantics and those with like phonology and dissimilar semantics. Regarding the visual span, EG subjects experienced greater difficulty in recall in direct and reverse order than CG subjects, with both groups encountering greater difficulty in recall in reverse order, as is explained by the need for greater attentional control, cognitive flexibility and planning in selecting a strategy to invert items displayed visually (Hasselhorn \& Grube, 2003; Ferreira, 2011; Sagrilo \& Ferreira, 2012). CG subjects performed substantially better in recalling words in reverse order than their EG counterparts, in conformity with Andrade's research (2002). This type of task demands greater use of attention as it is not an everyday activity. In recall in reverse order, the last words on the list are more readily recalled since less time has ensued and therefore they have yet to suffer temporal degradation, while retaining more phonological support (Hulme \& Tordoff, 1989; Rapport, Alderson, Kofler et al., 2008).

In order to assist the understanding of the functioning of working memory in children with ADHD, it is suggested a future study of this ability within each subtype, in order to check the working memory performance among inattentive, hyperactive and combined. 


\section{Conclusion}

In conclusion, in assessing the overall performance of both groups in terms of phonological working memory, a significant difference was observed, with EG underperforming CG. The lower performance for children with ADHD reported in this study corroborates the findings of previous research (Andrade, 2002; Schweitzer, Faber, Grafton et al., 2000; Rapport, Alderson, Kofler et al., 2008).

Notwithstanding the dearth of studies on the effects of similarity in working memory, this study suggests some characteristics of the performance profile of children with ADHD in that regard. It was observed that such subjects present auditory and visual changes in WM. This commends consideration of enhanced focusing in rehabilitation on auditory aspects to minimize the cognitive-linguistic changes and maximize learning potential.

\section{References}

Abad-Mas, L, Ruiz-Andres, R., Moreno-Madrid, F. et al. (2011). Entrenamiento de funciones ejecutivas en el trastorno por deficit de atencion/ hiperactividad. Rev Neurologia, 52, S77-S83.

American Psychiatric Association (APA) (1994). Diagnostic and Statistical Manual of Mental Disorders (4 ${ }^{\text {th }}$ ed.). Washington DC: American Psychiatric Association.

Andrade, E. R. (2002). Memória de trabalho verbal e visual em crianças com transtorno do déficit de atenção/ hiperatividade. São Paulo: Dissertação de Mestrado, Faculdade de Medicina, Universidade de São Paulo.

Baddeley, A. D. (2000). The Episodic Buffer: A New Component of Working Memory? Trends Cognitive Science Kidlington, 4, 417-423. http://dx.doi.org/10.1016/S1364-6613(00)01538-2

Barkley, R. A. (2008). Transtorno do Déficit de Atenção e Hiperatividade: Manual para diagnóstico e tratamento. Porto Alegre: Artmed.

Farrel, S. (2006). Mixed-List Phonological Similarity Effects in Delayed Serial Recall. Journal of Memory and Language, 55, 587-600. http://dx.doi.org/10.1016/j.jml.2006.06.002

Ferreira, T. L. (2011) Avaliação da memória de trabalho auditiva e visual em escolares com transtorno do déficit de atenção e hiperatividade. Campinas: Dissertação de Mestrado, Faculdade de Ciências Médicas, Universidade Estadual de Campinas.

Golfeto, J. H., \& Barbosa, G. (2004). Epidemiologia. In L. A. Rohde, \& P. Mattos (Eds.), Princípios e práticas em TDAH. Porto Alegre: Artmed, 15-34.

Hasselhorn, M., \& Grube, D. (2003). The Phonological Similarity Effect on Memory Span in Children: Does It Depend on Age, Speech Rate, and Articulatory Suppression? International Journal of Behavioral Development, 27, 145-152. http://dx.doi.org/10.1080/01650250244000146

Hulme, C., \& Tordoff, V. (1989). Working Memory Development: The Effects of Speech Rate: Word Lenght and Acoustic Similarity on Serial Recall. Journal of Experimental Child Psychology, 47, 72-87. http://dx.doi.org/10.1016/0022-0965(89)90063-5

Kofler, M. J., Rapport, M. D., Bolden, J., Sarver, D. E., \& Raiker, J. S. (2010). ADHD and Working Memory: The Impact of Central Executive Deficits and Exceeding Storage/Rehearsal Capacity on Observed Inattentive Behavior. Journal of Abnormal Child Psychology, 38, 149-161. http://dx.doi.org/10.1007/s10802-009-9357-6

Li, X. J., Schweickert, R., \& Gandour, J. (2000). The Phonological Similarity Effect in Immediate Recall: Positions of Shared Phonemes. Memory \& Cognition, 28, 1116-1125. http://dx.doi.org/10.3758/BF03211813

Lopes, E. J., Lopes, R. F. F., \& Galera, C. A. (2005). Memória de trabalho viso-espacial em crianças de 7 a12 anos. Estudo de Psicología, 10, 54-61.

Lovatt, P., Avons, S. E., \& Masterson, J. (2000). The Word-Length Effect and Disyllabic Words. The Quarterly Journal of Experimental Psychology, 53A, 1-22. http://dx.doi.org/10.1080/713755877

Mulas, F., Gandía, R., Roca, P., Etchepareborda, M. C., \& Abad, L. (2012). Actualización farmacológica em el trastorno por déficit de atención/hiperactividad: Modelo de intervención y nuevos fármacos. Revista de Neurologia, 54, S41-S53.

Polanczyk, G., Laranjeira, R., Zaleski, M., Pinsky, I., Caetano, R., \& Rohde, L. A. (2010). ADHD in a Representative Sample of Bazilian Population: Estimated Prevalence and Comparative Adequacy of Criteria between Adolescents and Adults According to the Item Response Theory. International Journal of Methods Psychiatry Research, 19, 177-184.

Rapport, M. D., Alderson, R. M., Kofler, M. J., Sarver, D. E., Bolden, J., \& Sims, V. (2008). Working Memory Deficits in Boys with Attentions-Deficit Hyperactivity Disorder (ADHD): The Contribution of Central Executive and Subsystem Processes. Journal of Abnormal Child Psychology, 36, 825-837. http://dx.doi.org/10.1007/s10802-008-9215-y

Rodrigues, A., \& Befi-Lopes, D. (2009). Memória operacional fonológica e suas relações com o desenvolvimento da linguagem infantil. Pró-Fono Revista de Atualização Científica, 21, 63-69. 
http://dx.doi.org/10.1590/S0104-56872009000100011

Rohde, L. A. (2008). Is There a Need to Reformulate Attention Deficit Hyperactivity Disorder Criteria in Future Nosologic Classifications? Child and Adolescent Psychiatric Clinics of North America, 17, 405-420. http://dx.doi.org/10.1016/j.chc.2007.11.007

Sagrilo, M. C. P., \& Ferreira, T. L. (2012). Diferença entre span auditivo e visual nos gêneros: Estudo piloto. Revista CEFAC, 15, 552-560. http://dx.doi.org/10.1590/S1516-18462012005000061

Sánchez-Mora, C., Ribasés, M., Mulas, F., Soutullo, C., Sants, A., Pàmias, M., Casas, M., \& Ramos-Quiroga, J. A. (2012). Bases genéticas del trastorno por déficit de atención/hiperactividad. Revista de Neurologia, 55, 609-618.

Schoemaker, K., Bunte, T., Wiebe, S. A., Espy, K. A., Dekovic, M., \& Matthys, W. (2012). Executive Function Deficits in Preschool Children with ADHD and DBD. Journal of Child Psychology and Psychiatry, 53, 111-119. http://dx.doi.org/10.1111/j.1469-7610.2011.02468.x

Schweitzer, J. B., Faber, T. L., Grafton, S. T., Tune, L. E., Hoffman, J. M., \& Kilts, C. D. (2000). Alterations in the Functional Anatomy of Working Memory in Adult Attention Deficit Hyperactivity Disorder. American Journal of Psychiatry, 157, 278-280. http://dx.doi.org/10.1176/appi.ajp.157.2.278

Tiffin-Richards, M. C., Hasselhorn, M., Woerner, W., Rothenberger, A., \& Banaschewski, T. (2008). Phonological ShortTerm Memory and Central Executive Processing in Attention-Deficit Hyperactivity Disorder with Dyslexia-Evidence of Cognitive Overlap. Journal of Neural Transmission, 115, 227-234. http://dx.doi.org/10.1007/s00702-007-0816-3

Uehara, E., \& Landeira-Fernandez, J. (2010). Um panorama sobre o desenvolvimento da memória de trabalho e seus prejuízos no aprendizado escolar. Ciências e Cognição, 15, 31-41.

Vancer, A., Ferrin, M., Winther, J., \& Gomez, R. (2013). Examination of Special Working Memory Performance in Children and Adolescents with Attention Deficit Hyperactivity Disorder, Combined Type (ADHD-CT) and Anxiety. Journal of Abnormal Child Psychology, 41, 891-900. http://dx.doi.org/10.1007/s10802-013-9721-4

Walshaw, P., Alloy, L. B., \& Saab, F. W. (2010). Executive Function in Pediatric Bipolar Disorder and Attention-Deficit Hyperactivity Disorder: In Search of Distinct Phenotypic Profiles. Neuropsychological Review, 20, 103-120.

http://dx.doi.org/10.1007/s11065-009-9126-x 